\title{
Bronchiolitis obliterans following haematopoietic stem cell transplantation
}

\author{
A.O. Soubani* and J.P. Uberti ${ }^{\#}$
}

ABSTRACT: The aim of the present article is to review the available clinical data on bronchiolitis obliterans following haematopoietic stem cell transplantation (HSCT).

The data sources used were the Medline database and references from the identified articles related to bronchiolitis obliterans, noninfectious pulmonary complications and HSCT.

HSCT is an important treatment for a variety of malignant and nonmalignant conditions. However, the procedure is limited by significant complications that may involve every organ of the body. Pulmonary complications are seen in $40-60 \%$ of HSCT recipients. The recent advances in prophylaxis and treatment of infectious complications have increased the significance of late noninfectious pulmonary conditions.

Currently, bronchiolitis obliterans is one of the most challenging pulmonary complications facing clinicians who are taking care of haematopoietic stem cell transplantation recipients. This article reviews the clinical and pathological features of this condition, sheds some light on potential mechanisms of pathogenesis, and discusses the available management options.

\section{KEYWORDS: Bone marrow transplantation, bronchiolitis}

B ronchiolitis obliterans (BO) is the most common late noninfectious pulmonary complication following allogeneic haematopoietic stem cell transplantation (HSCT). It is characterised by the onset of new air flow obstruction (AFO) following HSCT. It was first described following HSCT by BESCHORNER et al. [1] in 1978, who reported lymphocytic bronchitis in $10 \%$ of autopsies from patients who died following HSCT. In 1982, RocA et al. [2] described fatal BO in a patient with a severe chronic graft versus host disease (GVHD) following HSCT. Since then, many reports have described this complication following HSCT (table 1), however, these reports are retrospective and are based on small case series. Furthermore, they lack uniform diagnostic criteria or management approach. The present review discusses the incidence, pathogenesis, clinical features and the management approaches of BO following HSCT.

\section{INCIDENCE}

The incidence of $\mathrm{BO}$ varies widely in different reports, in part due to the lack of a standardised definition. The reported incidence range is $0-48 \%$ (table 1). In a review of 2,152 allogeneic HSCT recipients reported in nine studies, the average incidence of $\mathrm{BO}$ was $8.3 \%$ [27]. In a recent report from Seattle (WA, USA), the incidence of BO in 1,131 allogeneic HSCT recipients was 26\%; however, in patients with chronic GVHD, the incidence of BO was 32\% [19]. The International Bone Marrow Transplantation Registry (IBMTR) reported that the incidence of $\mathrm{BO}$ was $1.7 \%$ 2 yrs after transplantation in 6,275 patients who received matched sibling HSCT [26]. One report specifically commented on the incidence of $\mathrm{BO}$ following peripheral blood stem cell transplantation and showed that there was three-fold increase in the risk of $\mathrm{BO}$ compared with bone marrow transplantation (BMT; hazard ratio 3.35; $95 \%$ confidence interval $(\mathrm{CI}) 1.79-6.27 ; \mathrm{p}=0.0002)$ [26]. Regarding the incidence of $\mathrm{BO}$ in relation to the intensity of the conditioning regimen, one study reported that the incidence of $\mathrm{BO}$ following nonmyeloablative HSCT was $2.3 \%$ compared with $17 \%$ following conventional myeloablative HSCT [25]. The difference between these two groups was statistically significant, but the clinical course and outcome of $\mathrm{BO}$ was similar. In general, BO does not develop following autologous HSCT. There are only a few cases reported in the literature of $\mathrm{BO}$ developing following autologous HSCT with fatal outcome $[28,29]$. Furthermore, there are very few reports of $\mathrm{BO}$ proven by lung biopsy developing in
AFFILIATIONS

*Division of Pulmonary and Critical Care Medicine, and

"Blood and Marrow Stem Cell Transplant Program, Karmanos Cancer Center and Wayne State University School of Medicine, Detroit, MI, USA.

CORRESPONDENCE

A.0. Soubani

Division of Pulmonary Critical Care and Sleep Medicine Harper University Hospital 3990 John R-3 Hudson Detroit Ml 48201 USA Fax: 13139930562 E-mail: asoubani@med.wayne.edu Received: April 172006 Accepted after revision: October 242006

STATEMENT OF INTEREST None declared.

European Respiratory Journal Print ISSN 0903-1936 Online ISSN 1399-3003 


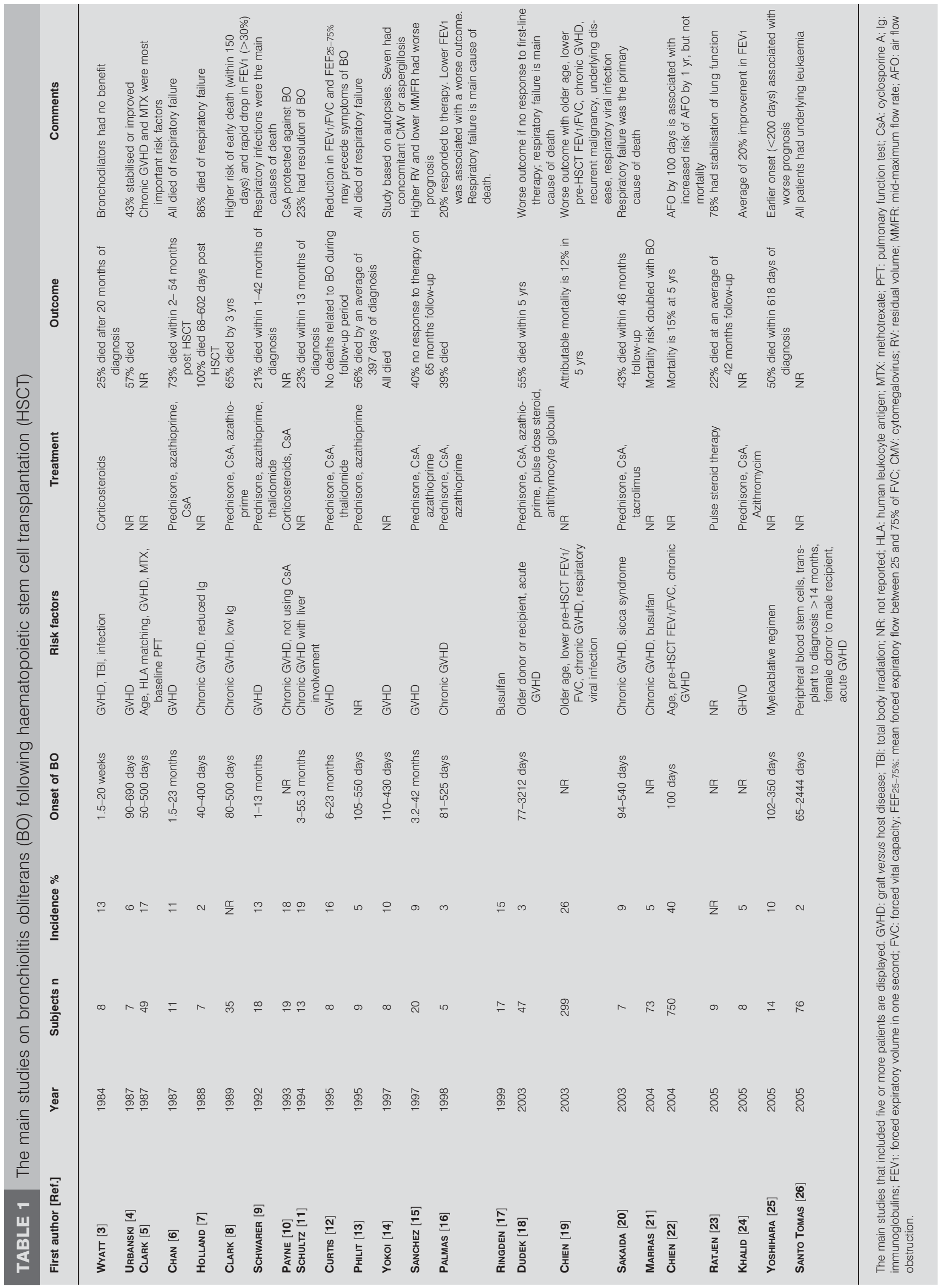


patients who received umbilical cord blood stem cell transplantation [30, 31].

\section{RISK FACTORS}

The main risk factors for BO following HSCT are summarised in table 2 [3-19, 20-22, 25, 32-34]. The most important association with $\mathrm{BO}$ is the presence of chronic GVHD. Earlier studies suggest that BO does not develop in patients without evidence of chronic GVHD [6, 11]. However, more recent studies from large HSCT centres report that BO may develop in a small percentage of patients who do not have manifestations of GVHD. In the IBMTR, 7\% of patients with a diagnosis of BO did not have chronic GVHD [26]. In a study of 360 patients with AFO following allogeneic HSCT, 63 (18\%) had no history of acute or chronic GVHD [19]. In this regard, the risk of $\mathrm{BO}$ appears to be higher in those with progressive chronic GVHD (which evolves without hiatus from active acute GVHD) as compared with those with quiescent chronic GVHD (that develops after an interval of response to treatment of acute GVHD) or de novo chronic GVHD (in patients who never had acute GVHD). In the study by CHIEN et al. [19], the adjusted relative risk for AFO obstruction was: 1.5 (95\% CI 0.8 2.0) with de novo chronic GVHD; 1.6 (1.3-2.4) with quiescent chronic GVHD; and 1.9 (1.4-2.4) with progressive chronic GVHD. The difference between these different forms was statistically significant. In the majority of reports, acute GVHD alone does not appear to significantly increase the risk of $\mathrm{BO}$. Other frequently observed risk factors for BO include: an older age of the recipient $(>20 \mathrm{yrs}$ ); the presence of AFO (forced expiratory volume in one second (FEV1)/forced vital capacity $(\mathrm{FVC})<70 \%$ ) prior to HSCT; and respiratory viral infections, such as influenza, parainfluenza and respiratory syncytial virus, in the first 100 days following HSCT [19, 22]. There are other risk factors for $\mathrm{BO}$ that have been described by some studies, but not consistently so, and these include a busulfanbased conditioning regimen, mismatched or unrelated donor, hypogammaglobulinaemia (especially immunoglobulin (Ig)G and $\operatorname{IgA}$ ), methotrexate prophylaxis against GVHD, older age of the donor, and HSCT for chronic myelogenous leukaemia [5, $7,8,17,21]$. In the report by the IBMTR [26], the risk factors for $\mathrm{BO}$ on multivariate analysis were blood-derived stem cells, a busulfan-based conditioning regimen, interval from diagnosis of leukaemia to transplantation $>14$ months, female donor to male recipient, prior interstitial pneumonitis, and an episode of moderate-to-severe acute GVHD.

\section{CLINICAL PRESENTATION}

$\mathrm{BO}$ is a late complication of allogeneic HSCT that usually presents after the first 100 days following transplantation $[3,5$, $7,8,14,18,22]$. Although there are reports of $\mathrm{BO}$ as early as 30 days following HSCT, $\sim 80 \%$ of cases present between 6 and 12 months post-transplantation $[7,6,13]$. In the report by the IBMTR, the median interval from HSCT to diagnosis of BO was 431 days (range 65-2,444 days) post-transplantation [26]. The presentation of $\mathrm{BO}$ is usually insidious. In total, $23 \%$ of patients describe antecedent upper respiratory tract symptoms [8]. The main symptoms associated with BO are dry cough (60-100\%) and dyspnoea $(50-70 \%)[6,8,12,35]$. Wheezing and sinusitis are other frequent symptoms [8]. Fever is rare unless there is a concomitant infectious process. Approximately $20 \%$ of patients are asymptomatic and the diagnosis is suspected based on pulmonary function test (PFT) findings [8]. In the advanced stages of $\mathrm{BO}$, the patients are physically limited due to severe obstructive airway disease and may require home oxygen therapy. Some patients may develop features of bronchiectasis with recurrent respiratory tract infections and colonisation of the airways by Pseudomonas spp., Staphylococcus aureus and, occasionally, Aspergillus spp.

On examination, the patients usually have signs of hyperinflation and decreased breath sounds. Wheezing and inspiratory squeaks may also be present. Basal crackles are rare. Conversely, the thoracic examination may be completely normal, especially in early stages $[8,36]$. Almost all patients with $\mathrm{BO}$ have signs and symptoms of chronic GVHD, especially skin changes and sicca syndrome, with dryness in the eyes and mouth. In the data provided by the IBMTR on 6,275 patients, all except five had manifestations of GVHD [26].

The clinical course of $\mathrm{BO}$ is variable. The majority of patients have a slow progressive AFO, with episodes of acute exacerbation of AFO. In the minority of patients, the AFO progresses rapidly and patients develop respiratory failure within a few months. However, some patients may have stabilisation or even improvement in the AFO [11, 16].

\section{RADIOLOGICAL EVALUATION}

In the early stages of $\mathrm{BO}$, the chest radiograph is normal. The presence of parenchymal changes suggests an infection or an unrelated process. As BO becomes more advanced, there are signs of hyperinflation on the chest radiograph and, later, there are changes consistent with bronchiectasis with dilated and thickened bronchi and areas of scarring. Pneumothorax, pneumomediastinum, and pneumopericardium may develop in advanced cases, and are usually associated with significant morbidity and mortality [5, 37-39].

High-resolution computed tomography (HRCT) of the chest is much more sensitive in detecting signs of $\mathrm{BO}$ and is the radiological procedure of choice in evaluating these patients [40-42]. While the study may still be normal in the early stages of $\mathrm{BO}$, it usually shows signs of hyperinflation with areas of decreased attenuation. Bronchiectasis is seen in advanced cases. However, the most common radiological sign of $\mathrm{BO}$ on HRCT of the chest is the presence of air trapping during the expiratory phase of imaging. These views show areas of hypoattenuation that correspond to obstructed airways interspaced with areas of ground glass appearance corresponding to the pulmonary lobules with patent airways. This "mosaic" appearance is highly suggestive of $\mathrm{BO}$, and has sensitivity and specificity in the diagnosis of $\mathrm{BO}$ with ranges between $74-91 \%$ and $67-94 \%$, respectively [43-45]. Some studies demonstrated that the presence of expiratory air trapping preceded the PFT criteria for BO [44]. In a study of 11 patients with $\mathrm{BO}$ following HSCT who underwent HRCT of the chest, all were found to have abnormal findings, and all patients had progression of radiological findings over time [41]. The most common finding was decreased lung attention, especially in the lower lobes, and expiratory air trapping $(n=11)$. Other common findings were subsegmental bronchial dilatation $(n=6)$, diminishing of peripheral vascularity $(n=6)$, centrilobular nodules, believed to be due to inspissated secretions in the distal airways, or plugging of the terminal bronchioles by granulation tissues 


$\begin{array}{ll}\text { TABLE } 2 & \begin{array}{l}\text { The risk factors for bronchiolitis obliterans } \\ \text { following haematopoietic stem cell } \\ \text { transplantation (HSCT) }\end{array} \\ \text { Consistent } & \text { Allogeneic HSCT } \\ & \text { Progressive chronic GVHD } \\ \text { Probable } & \text { De novo or quiescent chronic GVHD } \\ & \text { Older age of recipient } \\ & \text { AFO prior to HSCT } \\ & \text { Early respiratory viral infection } \\ \text { Possible } & \text { Acute GVHD } \\ & \text { Busulfan-based conditioning regimen } \\ & \text { Total body irradiation } \\ & \text { Methotrexate-based GVHD prophylaxis } \\ & \text { Hypogammaglobulinaemia } \\ & \text { CMV infection } \\ & \text { Older age of donor } \\ \text { Underlying diseases (CML) } \\ \text { Gastro-oesophageal reflux disease }\end{array}$

GVHD: graft versus host disease; AFO: air flow obstruction; CMV: cytomegalovirus; CML: chronic myelogenous leukaemia.

$(n=4)$. In addition, HRCT of the chest is very helpful in excluding co-existing conditions such as infections, bronchiolitis obliterans organising pneumonia (BOOP), or idiopathic pneumonia syndrome [16]. In summary, it is recommended that a HRCT of the chest with inspiratory and expiratory views be performed on all patients under evaluation for $\mathrm{BO}$ following HSCT.

\section{BRONCHOSCOPY}

Bronchoscopy has a limited role in the diagnosis of $\mathrm{BO}$ following HSCT. Bronchoalveolar lavage (BAL) is mainly carried out to rule out an infectious process in HSCT recipients who present with respiratory symptoms suggestive of $\mathrm{BO}$. This is especially the case when there are infiltrates on chest radiograph or HRCT of the chest, or in the presence of fever. The main infections to be considered in this setting, and in which BAL may be useful, are viral infections such as cytomegalovirus (CMV), respiratory syncytial virus, influenza, parainfluenza, or herpes simplex virus. In addition, fungal infections and Pseudomonas carinii need to be considered if the patient is on systemic corticosteroids and/or immunosuppressive therapy [46].

BAL has also been studied to evaluate the cellular and chemical profile in patients with BO following HSCT. A few studies have demonstrated that there is neutrophil predominance in the BAL fluid in patients with BO following HSCT [47]. In a study of 12 patients with $\mathrm{BO}$ in whom BAL was carried out, five patients had predominance of neutrophils, while three had mainly lymphocytes in the lavage fluid [48]. In addition, BAL may be useful in the analysis of cytokines in patients with BO. A study compared HSCT recipients who had infectious pneumonia $(n=14)$ to another group with idiopathic pneumonia syndrome or BO $(n=6)$. The level of tumour necrosis factor (TNF)- $\alpha$ in the BAL fluid was significantly higher in the latter group [49]. Higher levels of TNF- $\alpha$ were associated with a worse outcome.
Bronchoscopy and BAL is generally well tolerated in patients with $\mathrm{BO}$; however, caution should be exercised in patients with advanced disease, since the procedure may precipitate an acute AFO or pneumothorax [38,50]. Another observation is that the BAL fluid return is usually scarce in patients with advanced $\mathrm{BO}$ due to the narrowing and collapsibility of the smaller airways [34].

Transbronchial biopsy has a limited role and is generally not recommended for the diagnosis of BO following HSCT. This is due to the fact that the disease is patchy and peripheral, and the biopsy sample obtained by this procedure is usually too small to show bronchiolar pathology. If histological confirmation of $\mathrm{BO}$ is necessary, then the best approach is a surgical lung biopsy obtained by video-assisted thoracoscopy. However, this procedure is rarely indicated for the diagnosis of BO following HSCT in clinical practice. YOUSEM [51] reviewed the histological findings of lung biopsies in 17 HSCT patients with GVHDrelated pulmonary disease. Five patients had $\mathrm{BO}$, and the biopsies showed cicatricial $\mathrm{BO}$, in which the lumens of airways were obliterated by dense fibrous scar tissue. Some of these airways displayed eccentric subepithelial fibrous plagues. The epithelial cells were flattened at some locations, while other sites displayed metaplasia or hyperplasia. There was peribronchiolar mononuclear cellular inflammation, but no alveolar or interstitial involvement. The author's theory on the sequence of events leading to $\mathrm{BO}$ in these patients is that infiltration of the submucosa of the smaller airways by lymphocytes occurs. These cells migrate through the basement membrane of respiratory epithelium leading to epithelial cell necrosis and areas of ulceration. Myofibroblasts then grow through these denuded areas and deposit young collagen, creating intraluminal granulation tissue and scarring.

\section{PULMONARY FUNCTION TESTS}

Spirometry is the main study used to diagnose and follow-up patients with BO following HSCT. Spirometry usually shows evidence of AFO with reduction in FEV1 and FEV1/FVC. However, there has been a lack of consensus on the spirometric criteria for the diagnosis of BO following HSCT. Most of the studies define $\mathrm{AFO}$ as the new onset of drop in FEV1, with an FEV1/FVC ratio $<0.7[6-8,13,20]$. Some specify the drop in FEV1 to $>20 \%$ from baseline, or FEV1 $<80 \%$ of predicted with FEV1/FVC $<0.7[8,52]$. Others focus on the reduction in the FEV1/FVC ratio alone, and consider a drop in this ratio of $>20 \%$ following HSCT to be suggestive of BO [21]. In a large study of 1,131 allogeneic HSCT recipients, the authors used the definition of AFO as an annualised decline in FEV1 posttransplantation of $>5 \%$ per year with the lowest documented FEV1/FVC $<0.8$ [19]. Furthermore, there are some studies that suggest that a reduction in mean forced expiratory flow between 25 and $75 \%$ of FVC (FEF25-75\%) may precede the decline in FEV1, and is a sensitive but nonspecific indicator of subsequent development of BO [53-56]. Another study defined $\mathrm{AFO}$ as $\mathrm{FEV} 1<80 \%$ and $\mathrm{FEF} 25-75 \%<60 \%$ of predicted [11]. It appears from the collective literature that the most clinically relevant spirometric criteria of BO following HSCT are FEV1/ FVC $<0.7$, and a reduction in FEV $1>20 \%$ from the pretransplantation value. A drop in FEV1 $<20 \%$ from baseline should alert clinicians to follow-up on those patients more carefully for signs of BO. 
Other PFT findings consistent with BO include lack of significant improvement in FEV1 post-bronchodilator treatment, increased residual volume and residual volume/total lung capacity ratio (consistent with air trapping), and increased airway resistance [6, 8]. Reduction in diffusion capacity is not a feature of $\mathrm{BO}$, however, these patients commonly have a reduced diffusing capacity of the lung for carbon monoxide [57]. This finding is most likely to be related to other factors, such as high-dose chemotherapy, idiopathic pneumonia syndrome, or infections.

The spirometric findings of AFO are usually detected after the first 100 days following HSCT. The relation between detecting AFO prior to the first 100 days following HSCT and the development of long-term AFO and BO mortality was studied by CHIEN et al. [22]. The authors reviewed 1,892 myeloablative allogeneic HSCT who had PFT during the first 100 days following transplantation. Of these, $40 \%$ had AFO by day 100; however, only $26 \%$ had AFO 1 yr following transplantation. The presence of early AFO was associated with an increased risk of long-term AFO, but not with increased mortality. Moreover, patients who had the fastest decline in FEV1 $(>10 \%$ per year) between day 100 and $1 \mathrm{yr}$, had the highest mortality risk. This study suggests that it is useful to monitor PFT early (around 100 days) following HSCT, and closely monitor those with evidence of AFO, since these patients are at an increased risk for long-term AFO. Conversely, the study suggests that early AFO may be reversible in some patients. More studies are needed to identify the clinical characteristics of those patients who demonstrated reversible AFO.

As suggested above, one of the main problems facing the management of BO following HSCT is a lack of standardised criteria for its diagnosis. Recently, the National Institutes of Health (NIH) sponsored a consensus development project for clinical trials on chronic GVHD [58]. The workshop considered $\mathrm{BO}$ as the only diagnostic manifestation of chronic GVHD in the lung, and suggested that the diagnosis of $\mathrm{BO}$ is made when: 1) there is evidence of AFO with FEV1/FVC $<0.7$ and FEV1 $<75 \%$ of predicted; 2 ) there is evidence of air trapping or small airway thickening or bronchiectasis on HRCT of the chest with inspiratory and expiratory cuts, residual volume on PFT $>120 \%$ of predicted or pathological confirmation of constrictive bronchiolitis; and 3) absence of infection in the respiratory tract documented by clinical symptoms, radiological studies or microbiological cultures, obtained by sinus aspirate, upper respiratory tract viral screen, sputum culture or BAL. In addition, the statement mentioned that BOOP, not due to an infectious process, may represent a manifestation of either acute or chromic GVHD. Table 3 proposes diagnostic criteria of BO following HSCT that are based on clinical features, radiological and spirometric studies, and absence of infectious processes. Another significant decision by the NIH Consensus Development Project is to include BO in the scoring system for chronic GVHD following HSCT. Table 4 summarises the pulmonary scoring of chronic GVHD suggested by this workshop [58].

It is important in this context to differentiate between $\mathrm{BO}$ and BOOP [51,59]. Although these two terms are commonly used interchangeably, they are two different entities with different clinical and pathological features and different outcomes. Table 5 shows the differences between these two diagnoses.

\section{PATHOGENESIS}

The pathogenesis of BO is not completely understood. Several theories have been suggested, although none satisfactorily explains the pathogenesis of $\mathrm{BO}$. One of these theories is that $\mathrm{BO}$ is a lung injury precipitated by the conditioning regimen. This is based on the higher incidence of $\mathrm{BO}$ in busulfan-based conditioning regimen [17, 21], and the apparent lower incidence of BO in nonmyeloablative HSCT compared with conventional regimen [25].

Another proposed mechanism for the development of $\mathrm{BO}$ is that it is related to infectious processes. This mechanism is supported by different observations including the association of BO with low serum Igs $[6,7,36]$. This may lead to abnormal local defence mechanisms in the lungs, predisposing to unidentified infections that precipitate BO. This is also suggested by the observation that allogeneic HSCT recipients who develop respiratory viral infections early in the course following transplantation are at an increased risk of developing BO [19]. In addition, there is some evidence that chronic GVHD is associated with impaired mucociliary transport, which may lead to recurrent bronchial infections that may precipitate $\mathrm{BO}$ [60]. Also, CMV infection has been suggested as one causative agent of $\mathrm{BO}$ following lung transplantation, which is similar to BO following HSCT [61]. Furthermore, BO is known to develop following infection by respiratory syncytial virus, parainfluenza, influenza, adenovirus, measles, and mycoplasma in nontransplant patients [36, 62]. Thus, a subtle infection may still be an important mechanism in the pathogenesis of $\mathrm{BO}$, although there is no exclusive evidence to prove this theory.

There are a few reports that suggest $\mathrm{BO}$ to be the end of the spectrum of acute lung injury following HSCT. In a case report of a patient who underwent allogeneic HSCT, and was thoroughly investigated for pulmonary problems by serial PFT, HRCT of the chest, bronchoscopies with BAL examination and transbronchial biopsies, and eventually by open lung biopsy, the authors argued that the patient developed interstitial pneumonitis, then BOOP, and eventually BO [47]. In discussing the histological findings of pulmonary disease associated with GVHD following HSCT, YOUSEM [51] suggested that BO seemed to represent the late stages of BMTassociated lymphocytic bronchiolitis and BOOP, and reflected irreversible pulmonary GVHD.

Another potential mechanism contributing to $\mathrm{BO}$ is recurrent aspiration due to oesophagitis associated with chronic GVHD. Microaspirations may promote chronic inflammation and recurrent infections in the lower airways that may lead to BO. Recurrent microaspiration has been suggested as one of the mechanisms of BO following lung transplantation [63-65]. Furthermore, gastro-oesophageal reflux disease (GERD) with recurrent microaspirations has been suggested as contributing to the pathogenesis of other pulmonary diseases [66].

The most important mechanism contributing to $\mathrm{BO}$ is probably an alloreactive immune process in which the donor T-lymphocytes target the epithelial cells of the bronchioles, leading to the inflammatory reaction seen in BO. This 
TABLE 3 Suggested diagnostic criteria of broncholitis obliterans (BO) following haematopoietic stem cell transplantation (HSCT)

Allogeneic HSCT

Chronic GVHD\#

Insidious onset of dyspnoea, cough and wheezing after 100 days following transplantation

Normal chest radiograph

HRCT of the chest (with inspiratory and expiratory views) showing areas of air trapping on expiratory views, hyperinflation or bronchial dilatation, with no parenchymal involvement

PFT showing new onset of airflow obstruction (FEV $1 / F V C<0.7$ and $\mathrm{FEV}_{1}<75 \%$ of predicted), not responsive to bronchodilators

Exclusion of an infectious process by appropriate radiological, serological and microbiological studies (obtained by sinus aspirate, upper respiratory tract viral screen, sputum culture or BAL)

GVHD: graft versus host disease; HRCT: high-resolution computed tomography; PFT: pulmonary function test; FEV1: forced expiratory volume in one second; FVC forced vital capacity; BAL: bronchoalveolar lavage. \#: The risk of BO is highest with progressive chronic GVHD, but it may develop in patients with quiescent or de novo GVHD, or without chronic GVHD.

mechanism is evident from the exclusive occurrence of $\mathrm{BO}$ following allogeneic HSCT, and the strong association between $\mathrm{BO}$ and chronic GVHD. Indeed, some authors suggest that BO is a manifestation of chronic GVHD [51]. Also, the reported stabilisation of $\mathrm{BO}$ in some HSCT recipients by systemic corticosteroids and intensification of immunosuppressive therapy supports the immune basis of BO following HSCT. In a well-characterised murine BMT model, significant noninfectious damage occurred in the animals with GVHD that was characterised by a decrease in dynamic lung compliance and airway conductance [67]. There was also expansion of reactive donor T-lymphocytes in the recipient lungs, with increased levels of inflammatory cytokines, such as TNF- $\alpha$ and interferon- $\gamma$, in the BAL fluid of the affected animals. Pathological examination of those animals that had GVHD with lung involvement revealed pneumonitis and mononuclear infiltration of the bronchi. Depletion of the donor Tlymphocytes prevented the development of systemic GVHD but did not eliminate the lung injury, indicating that the lungs are probably susceptible to smaller number of T-lymphocytes. The lungs may also represent a sanctuary site for the donor Tlymphocytes, even when systemic tolerance between the donor and host is established.

These immune mechanisms are thought to trigger inflammatory reactions that lead to $\mathrm{BO}$. These inflammatory reactions are characterised by an increase in inflammatory cytokines, such as interleukin (IL)-1, IL-6, IL-8, IL-18 and TNF- $\alpha$ [68, 69]. In one study [49], 11 patients with pulmonary complications following allogeneic HSCT (six patients had idiopathic pneumonia syndrome and/or BO) who had BAL fluid analysis were compared with 11 healthy volunteers. The HSCT recipients with $\mathrm{BO}$ had significantly higher levels of lavage fluid TNF- $\alpha$ and IL-18 compared with the controls. It is also possible that the nitric oxide (NO) pathway plays a role in the inflammatory changes that lead to BO. In lung transplantation recipients with $\mathrm{BO}$, there are increased levels of inducible $\mathrm{NO}$ synthase (iNOS) mRNA activity in the epithelial cells and other cells in a heterotropic rat tracheal allograft [70]. Inhibition of iNOS was associated with increased intensity of $\mathrm{BO}$ in these animals, while treatment with L-arginine, a precursor of NO, significantly reduced the bronchiolar obliteration. Furthermore, increased concentration of exhaled NO was demonstrated in lung transplantation recipients with $\mathrm{BO}$ [71], and one case report of a patient with BOOP following HSCT [72].

In summary, while the exact mechanisms leading to $\mathrm{BO}$ are not known, there are theories that chemotherapy, infection and alloreactive immune reaction play a role in the pathogenesis of this condition. It is also possible that combinations of the different mechanisms lead to the development of BO following HSCT.

\section{MANAGEMENT}

There are no controlled trials on the management of $\mathrm{BO}$. The treatment approaches are based on small uncontrolled trials and expert opinions. However, in general, the management of $\mathrm{BO}$ is similar to that of chronic GVHD and consists of highdose systemic corticosteroids and reinstitution or augmentation of immunosuppressive therapy. Systemic corticosteroids

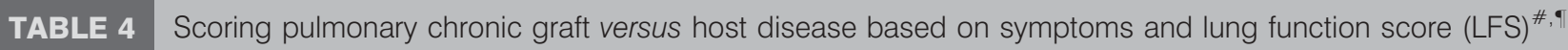

\begin{tabular}{llcl} 
& Score $\mathbf{0}$ & Score 1 & Score 2 \\
\hline Symptoms & No symptoms & $\begin{array}{c}\text { Shortness of breath on climbing } 3 \\
\text { one flight of steps }\end{array}$ & $\begin{array}{c}\text { Shortness of breath after walking } \\
\text { on flat ground } \\
\text { PFT }\end{array}$ \\
\hline
\end{tabular}

Data modified from [58]. PFT: pulmonary function test; FEV1: forced expiratory volume in one second. ${ }^{\#}$ : LFS is the sum of FEV 1 \% predicted and the \% predicted diffusing capacity of the lung for carbon dioxide corrected for haemoglobin. The values are converted to numeric score as follows: $>80 \%=1,70-79 \%=2 ; 60-69 \%=3 ; 50-$ $59 \%=4 ; 40-49 \%=5 ;<40 \%=6$. The possible range of LFS is $2-12 .{ }^{\circ}:$ When there is discrepancy between the symptoms and PFT scores, the higher value is used. 


\begin{tabular}{|c|c|c|}
\hline $\begin{array}{l}\text { Compa } \\
\text { haema }\end{array}$ & \multicolumn{2}{|c|}{$\begin{array}{l}\text { Comparison between broncholitis obliterans (BO) and broncholitis obliterans organising bacteria (BOOP) following } \\
\text { haematopoietic stem cell transplantation (HSCT) }\end{array}$} \\
\hline Features & BO & BOOP \\
\hline Incidence \% & $0-48$ & $<2$ \\
\hline Onset following HSCT & Late (around 1 yr) & Usually in the first 100 days \\
\hline Clinical presentation & Insidious; dyspnoea, cough, wheezing & Acute; dyspnoea, cough, fever \\
\hline Radiological findings & Normal; hyperinflation, air trapping, bronchiectasis & $\begin{array}{l}\text { Patchy consolidation (usually peripheral), ground } \\
\text { glass attenuation, nodular opacities }\end{array}$ \\
\hline PFT & Obstructive; normal $D\llcorner, \mathrm{CO}$ & Restrictive; reduction in $D \mathrm{~L}, \mathrm{CO}$ \\
\hline BAL & Predominantly neutrophils & Predominantly lymphocytes \\
\hline Diagnosis & Clinical criteria & Usually requires tissue, best by surgical lung biopsy \\
\hline Histopathology & $\begin{array}{l}\text { Granular plugs obliterating the bronchioles with inflammation } \\
\text { and scarring; sparing of the alveoli and alveolar ducts }\end{array}$ & $\begin{array}{l}\text { Granular plugs of bronchioles, extending to alveoli; } \\
\text { interstitial inflammation and fibrosis }\end{array}$ \\
\hline Treatment & Corticosteroids and immunosuppressive therapy & Corticosteroids \\
\hline Outcome & $\begin{array}{l}\text { Poor response to therapy; progressive disease with high } \\
\text { mortality }\end{array}$ & Good response to therapy; potentially reversible \\
\hline
\end{tabular}

PFT: pulmonary function test; $D L, C O$ : diffusing capacity of the lung for carbon monoxide; BAL: bronchoalveolar lavage.

are suggested in the form of prednisone at $1-1.5 \mathrm{mg} \cdot \mathrm{kg}^{-1} \cdot \mathrm{day}^{-1}$

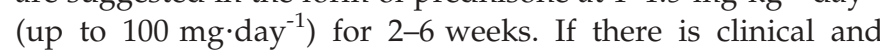
physiological stabilisation, the dose is tapered every 2 weeks for 6-12 months. This regimen is based on expert opinions and small case series rather than controlled trials $[3,8,10,15,18,27$, $34,73,74]$. The immunosuppressive agents used are similar to those used in the treatment of chronic GVHD, namely cyclosporine A or tacrolimus [10, 15, 16, 18, 20, 75]. In addition, azathioprime has been added in several studies in doses up to $3 \mathrm{mg} \cdot \mathrm{kg}^{-1} \cdot \mathrm{day}^{-1}$ (maximum $200 \mathrm{mg} \cdot \mathrm{day}^{-1}$ ) $[8,15,16,18]$. The dose of cyclosporine A should be adjusted to serum level. It is possible that early treatment may prevent the progression of AFO [22]. Conversley, it was observed that the rapid taper of cyclosporine A (for prophylaxis against GVHD) was associated with increased late noninfectious pulmonary complications, including BO [76]. Treatment is recommended for 312 months; however, some studies suggest that further improvement is unlikely after 9 months of treatment [15]. Other treatment options include "pulse" dose corticosteroid therapy. In a study of nine children with $\mathrm{BO}$, treatment with methylprednisolone at $10 \mathrm{mg} \cdot \mathrm{kg}^{-1} \cdot \mathrm{day}^{-1}$ for 3 days on monthly bases for 1-6 cycles led to stabilisation of FEV1 after 2 months of treatment; this was maintained during an average of $42 \pm 20$ months of follow-up [23]. Thalidomide and antithymocyte globulins have been used in few studies with variable results [77-82]. Also, i.v. immunoglobulins have been given to patients with $\mathrm{BO}$, with no proven benefit [83]. More recently, few reports suggest treating BO using anti-TNF- $\alpha$ (infliximab) [84]; however, there is no adequate data on the effectiveness of this therapy. Based on the experience using macrolides in the treatment of diffuse panbronchiolitis, cystic fibrosis and treatment of $\mathrm{BO}$ following lung transplantation, this class of medication is increasingly considered in the management of BO following HSCT [85-87]. Macrolides apparently downregulate pro-inflammatory cytokines, such as TNF- $\alpha$, so they may decrease the inflammatory reaction that leads to $\mathrm{BO}$ [87]. In a recent report of eight patients with $\mathrm{BO}$, azithromycin was added at a dose of $250 \mathrm{mg}$ three times a week for 12 weeks, and the authors reported an average of $281 \mathrm{~mL}(20.58 \%)$ improvement in FEV1 [24]. However, the value of adding such agents to the treatment regimen of patients with $\mathrm{BO}$ following HSCT is still not known, and it appears that the response to this treatment is variable.

The role of inhaled corticosteroids in the prevention and management of BO following HSCT has not been studied. There are very few reports on the addition of inhaled corticosteroids to the standard immunosuppressive regimen in the management of BO following lung transplantation [8892]. These reports do not show clinically significant benefit in the prevention or treatment of BO. One study reported that the addition of high-dose inhaled corticosteroids to the management of $\mathrm{BO}$ in 14 lung transplantation recipients resulted in reduction of exhaled NO concentration and improvement in FEV1 in the majority of these patients after 1-2.5 months of treatment [90]. Until large, placebo-controlled, multicentre trials are conducted to examine the role of inhaled corticosteroids in the prevention and management of $\mathrm{BO}$ following HSCT, it is reasonable to consider a trial of inhaled corticosteroids for 3 months, especially if there is evidence of reversibility in AFO on spirometry. If there is no benefit, then they may be discontinued. Patients should be treated with bronchodilators if they are symptomatic and during acute exacerbations of respiratory symptoms; however, most of the studies show that the reversibility in AFO with these agents is generally negligible $[3,8,13]$.

Extracorporeal photodynamic (ECP) therapy is another immunotherapeutic modality that has been used in the treatment of chronic GVHD and BO. This therapy is commonly used in the management of cutaneous T-cell lymphoma, scleroderma and other autoimmune disorders. It involves extracorporeal exposure of peripheral blood mononuclear cells to photoactivated 8-methoxypsoralen, by exposure to ultraviolet A light, followed by re-infusion of the treated cells [93]. The treatment is repeated every 2-3 weeks and continued for several months $[94,95]$. It is believed that the photoactivated 


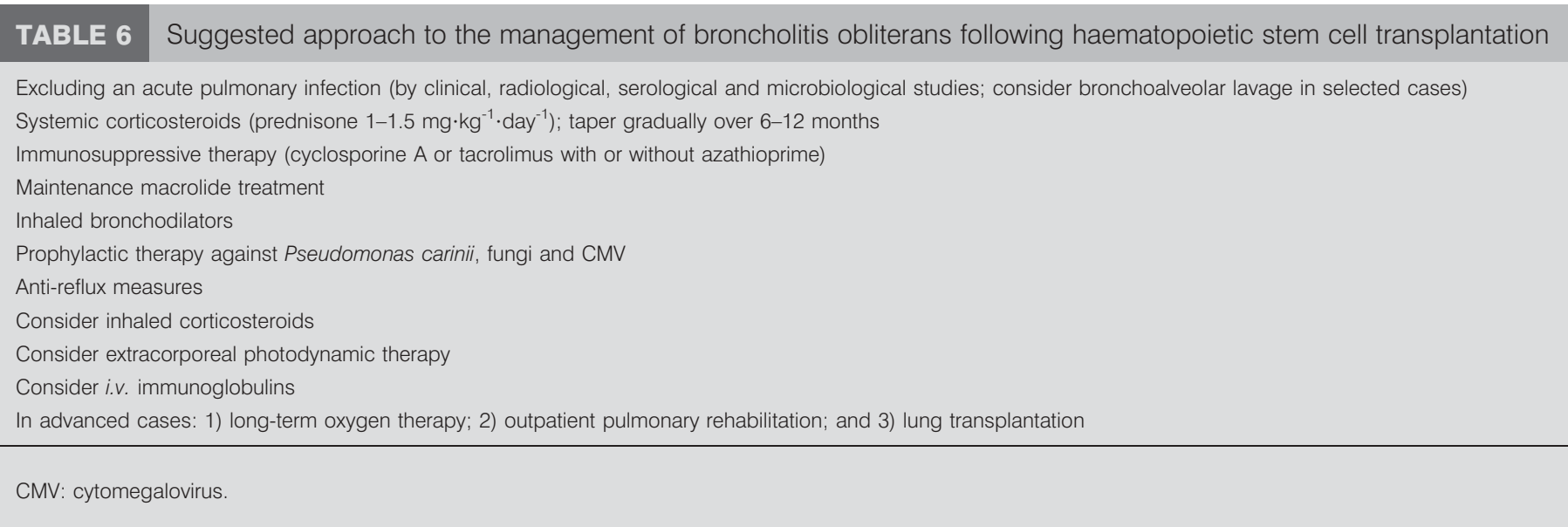

8-methoxypsoralen binds to DNA, leading to initiation of apoptosis, and that it has a selective effect on autoreactive Tcells $[93,96,97]$. These observations led to the use of ECP in the management of refractory acute and chronic GVHD. Several studies reported improvement in skin, mucus membrane, liver and pulmonary GVHD, resulting in fewer symptoms and tapering or discontinuation of immunosuppressive therapy $[94,95,98]$. The studies show that the best results are when ECP was started in the first 10 months following HSCT [99, 100]. Furthermore, these studies showed that this therapy is well tolerated and that there is no increased risk of infectious complications [99, 100].

The role of ECP in the management of $\mathrm{BO}$ following HSCT has not been well studied. The benefits are limited to case reports or small numbers of cases in small trials [95, 101, 102]. In a prospective study of 25 patients with steroid-refractory chronic GHVD, two patients had pulmonary GVHD, and both had partial improvement in lung function following ECP [95]. In another study of 22 patients with chronic GVHD treated by ECP, the overall response rate was $70 \%$, including two patients with BO who demonstrated improvement in lung function [101].

Supportive treatment is essential in the management of patients with BO following HSCT. Infectious processes should be excluded prior to starting immunosuppressive therapy. This is generally achieved by clinical and radiological evaluation, and routine serological and microbiological studies. Bronchoscopy with BAL is generally not necessary, except if there are pulmonary infiltrates or if the clinical presentation is atypical. Once immunosuppressive therapy is started, patients should be maintained on appropriate prophylactic measures against $P$. carinii. Prophylaxis against fungi and CMV should be considered in high-risk patients. In addition, appropriate vaccinations including influenza and pneumococcus are recommended. Prompt treatment of pulmonary infections is essential, since these tend to worsen the course and outcome of BO. Patients with advanced $\mathrm{BO}$ may require long-term oxygen therapy and may benefit from outpatient pulmonary rehabilitation.

Treatment of BO following HSCT is generally frustrating and response to the above approaches is marginal. Some patients may be considered for lung transplantation. There are a few reports of lung transplantation in patients with advanced BO with encouraging results [103-109]. In a review of nine patients who underwent such treatment, five patients had single lung transplantation, and four had double lung transplantation. The patients were followed up 9-72 months following lung transplantation. Three patients died of recurrent $\mathrm{BO}$, chronic rejection or infection. The rest were doing well with no signs of BO [109]. The role of lung transplantation in the management of BO following HSCT remains limited by the availability of donor organs, the small number of centres that would consider HSCT recipients, the risks of intensive immunosuppressive therapy, and the potential for recurrence of BO. Table 6 summarises the management approaches to $\mathrm{BO}$ following HSCT.

\section{PROGNOSIS}

$\mathrm{BO}$ following HSCT is a progressive disease that leads, in the majority of patients, to irreversible AFO. Aggressive therapy results in improvement of lung function in only $8-20 \%$ of patients $[4,7,11,16,110]$. The best expectations in the management of patients with $\mathrm{BO}$ are to stabilise and prevent further drops in FEV1. The mortality rate in patients with BO following HSCT varies $14-100 \%$, with a median of $65 \%$ [3, 6-8, $13,16,27,34]$. In a large cohort study of patients with AFO following HSCT, the attributable mortality was $9 \%$ at 3 yrs, $12 \%$ at $5 \mathrm{yrs}$, and $18 \%$ at $10 \mathrm{yrs}$, while the attributable mortality in those with associated chronic GVHD was $22 \%$ at $3 \mathrm{yrs}, 27 \%$ at $5 \mathrm{yrs}$, and $40 \%$ at $10 \mathrm{yrs}$ [19]. Most patients with BO progress to respiratory failure, and some patients develop bronchiectasis with frequent bacterial exacerbations. Patients with advanced BO usually die from pneumonia [7, 13, 18, 20].

Factors that are associated with increased mortality related to BO following HSCT include rapid deterioration of FEV1 $(>10 \%$ per year), age $>60$ yrs, progressive chronic GVHD, underlying disease risk at transplantation, underlying disease relapse and history of respiratory viral infection $[19,22,26]$. Another study showed that the prognosis of BO following HSCT is worse in patients who develop AFO early ( $<150$ days) following transplantation, and have rapid decline in FEV1 (>30\%) [8]. In addition, the prognosis of $\mathrm{BO}$ is worse if the patients do not respond to the primary treatment regimen [18]. The prognosis of $\mathrm{BO}$ appears not to be influenced by the presence of AFO prior to transplantation, the source of stem cells, degree of matching, CMV serological status or the type of GVHD prophylaxis [26]. 


\section{BRONCHIOLITIS OBLITERANS SYNDROME FOLLOWING LUNG TRANSPLANTATION}

The present review focuses on BO following HSCT; however, it is important to discuss the similarities and differences of this syndrome in lung transplantation and HSCT recipients. The diagnostic criteria for $\mathrm{BO}$ following lung transplantation are better defined and are universally adopted. The International Society for Heart and Lung Transplantation proposed the following classification of BO syndrome (BOS) following lung transplantation: BOS 0: FEV1 $>90 \%$ of baseline and FEF $25-75 \%$ $>75 \%$ of baseline; BOS 0-p: FEV1 81-90\% of baseline and/or FEF $25-75 \% \leqslant 75 \%$ of baseline; BOS 1: FEV1 $66-80 \%$ of baseline; BOS 2: FEV1 $51-65 \%$ of baseline; and BOS 3: FEV1 $\leqslant 50 \%$ of baseline [52].

While chronic GVHD is the only established risk factor for BO following HSCT, there are several factors strongly implicated in the pathogenesis of $\mathrm{BO}$ following lung transplantation, and these include allograft rejection and that $\mathrm{BO}$ represents chronic rejection. In addition, there is evidence that the severity of $\mathrm{BO}$ following lung transplantation correlates well with the onset, number and severity of acute rejection episodes, and that early and aggressive treatment of acute rejection appears to prevent BO [52, 111-113]. Conversely, it is not clear that aggressive treatment of GVHD is protective against BO following HSCT. Alloimmune independent factors also play an important role in the pathogenesis of $\mathrm{BO}$ following lung transplantation, and are mainly related to airway ischaemia during the time interval between organ procurement and transplantation, and interruption of bronchial arterial supply after re-implantation of the graft $[45,114,115]$. This ischaemia leads to lymphocytic infiltration and the development of lymphocytic bronchitis and bronchiolitis which is a precursor of $\mathrm{BO}$ following lung transplantation [116]. Similar to BO following HSCT, CMV, other respiratory viral infections and GERD may play a role in the onset or exacerbation of $\mathrm{BO}$ following lung transplantation.

The clinical and radiological presentations of the $\mathrm{BO}$ in both patient populations appear to be similar; however, the incidence of $\mathrm{BO}$ following lung transplantation is higher and is reported to range $50-60 \%$ in patients who survive for 5 yrs after surgery (versus $0-48 \%$ following HSCT) [117, 118]. In addition, BO following lung transplantation is diagnosed later, with median time to diagnosis 16-20 months (versus 6-12 months following HSCT) [45]. Transbronchial biopsies play a more important role in the management of $\mathrm{BO}$ following lung transplantation than in HSCT recipients. The role of this procedure is not to confirm the diagnosis of $\mathrm{BO}$, but rather to detect acute rejection. Some studies show that surveillance transbronchial biopsies have led to resolution or stabilisation of the condition in a large percentage of patients with earlystage BO following lung transplantation $[113,119]$. In addition, the role of exhaled gases and condensates, such as exhaled NO and carbonyl sulphide, in detecting and monitoring BO has been better studied in lung transplantation recipients than for HSCT, but their role remains poorly established [71].

The management of $\mathrm{BO}$ following lung transplantation is generally similar to that outlined for HSCT. Intensification of immunosuppressive therapy is the mainstay of therapy. Minimising the graft ischaemia time, early treatment of respiratory infections, and treatment of GERD have been emphasised in the prevention and management of $\mathrm{BO}$ following lung transplantation [61, 63-65]. There are more reports on BO following lung transplantation describing the improvement of lung function using maintenance therapy with macrolides [86]. In addition, a recent report suggests that inhaled cyclosporine A may extend the periods of chronic rejection-free survival, and may have an impact on the development of BO following lung transplantation [120]. Mortality due to $\mathrm{BO}$ following lung transplantation is generally higher than that reported following HSCT [117].

\section{FUTURE DIRECTIONS}

Advances in haematopoietic stem cell transplantation techniques, and prophylaxis and treatment of infections, have significantly decreased the risks of infectious complications following transplantation. As a result, late complications, including broncholitis obliterans, are increasingly becoming a major cause of morbidity and mortality following haematopoietic stem cell transplantation. The management of broncholitis obliterans has been frustrating, with patients developing progressive air flow obstruction. Future efforts should focus on establishing uniform diagnostic criteria for broncholitis obliterans following haematopoietic stem cell transplantation that could guide clinical practice and research efforts. More animal models and clinical studies are needed to elucidate the inflammatory and immune mechanisms that lead to broncholitis obliterans following haematopoietic stem cell transplantation. At the same time, multicentre prospective trials are essential to define the risk factors, clinical course and the best management approach to this condition.

\section{REFERENCES}

1 Beschorner WE, Saral R, Hutchins GM, Tutschka PJ, Santos GW. Lymphocytic bronchitis associated with graft-versus-host disease in recipients of bone-marrow transplants. N Engl J Med 1978; 299: 1030-1036.

2 Roca J, Granena A, Rodriguez-Roisin R, Alvarez P, Agusti-Vidal A, Rozman C. Fatal airway disease in an adult with chronic graft-versus-host disease. Thorax 1982; 37: 77-78.

3 Wyatt SE, Nunn P, Hows JM, et al. Airways obstruction associated with graft versus host disease after bone marrow transplantation. Thorax 1984; 39: 887-894.

4 Urbanski SJ, Kossakowska AE, Curtis J, et al. Idiopathic small airways pathology in patients with graft-versushost disease following allogeneic bone marrow transplantation. Am J Surg Pathol 1987; 11: 965-971.

5 Clark JG, Schwartz DA, Flournoy N, Sullivan KM, Crawford SW, Thomas ED. Risk factors for airflow obstruction in recipients of bone marrow transplants. Ann Intern Med 1987; 107: 648-656.

6 Chan CK, Hyland RH, Hutcheon MA, et al. Smallairways disease in recipients of allogeneic bone marrow transplants. An analysis of 11 cases and a review of the literature. Medicine (Baltimore) 1987; 66: 327-340.

7 Holland HK, Wingard JR, Beschorner WE, Saral R, Santos GW. Bronchiolitis obliterans in bone marrow transplantation and its relationship to chronic graft-vhost disease and low serum IgG. Blood 1988; 72: 621-627. 
8 Clark JG, Crawford SW, Madtes DK, Sullivan KM. Obstructive lung disease after allogeneic marrow transplantation. Clinical presentation and course. Ann Intern Med 1989; 111: 368-376.

9 Schwarer AP, Hughes JM, Trotman-Dickenson B, Krausz T, Goldman JM. A chronic pulmonary syndrome associated with graft-versus-host disease after allogeneic marrow transplantation. Transplantation 1992; 54: 10021008.

10 Payne L, Chan CK, Fyles G, et al. Cyclosporine as possible prophylaxis for obstructive airways disease after allogeneic bone marrow transplantation. Chest 1993; 104: 114-118.

11 Schultz KR, Green GJ, Wensley D, et al. Obstructive lung disease in children after allogeneic bone marrow transplantation. Blood 1994; 84: 3212-3220.

12 Curtis DJ, Smale A, Thien F, Schwarer AP, Szer J. Chronic airflow obstruction in long-term survivors of allogeneic bone marrow transplantation. Bone Marrow Transplant 1995; 16: 169-173.

13 Philit F, Wiesendanger T, Archimbaud E, Mornex JF, Brune J, Cordier JF. Post-transplant obstructive lung disease ("bronchiolitis obliterans"): a clinical comparative study of bone marrow and lung transplant patients. Eur Respir J 1995; 8: 551-558.

14 Yokoi T, Hirabayashi N, Ito M, et al. Broncho-bronchiolitis obliterans as a complication of bone marrow transplantation: a clinicopathological study of eight autopsy cases. Nagoya BMT Group. Virchows Arch 1997; 431: 275-282.

15 Sanchez J, Torres A, Serrano J, et al. Long-term follow-up of immunosuppressive treatment for obstructive airways disease after allogeneic bone marrow transplantation. Bone Marrow Transplant 1997; 20: 403-408.

16 Palmas A, Tefferi A, Myers JL, et al. Late-onset noninfectious pulmonary complications after allogeneic bone marrow transplantation. Br J Haematol 1998; 100: 680-687.

17 Ringden $\mathrm{O}$, Remberger $\mathrm{M}$, Ruutu $\mathrm{T}$, et al. Increased risk of chronic graft-versus-host disease, obstructive bronchiolitis, and alopecia with busulfan versus total body irradiation: long-term results of a randomized trial in allogeneic marrow recipients with leukemia. Nordic Bone Marrow Transplantation Group. Blood 1999; 93: 2196-2201.

18 Dudek AZ, Mahaseth H, DeFor TE, Weisdorf DJ. Bronchiolitis obliterans in chronic graft-versus-host disease: analysis of risk factors and treatment outcomes. Biol Blood Marrow Transplant 2003; 9: 657-666.

19 Chien JW, Martin PJ, Gooley TA, et al. Airflow obstruction after myeloablative allogeneic hematopoietic stem cell transplantation. Am J Respir Crit Care Med 2003; 168: 208-214.

20 Sakaida E, Nakaseko C, Harima A, et al. Late-onset noninfectious pulmonary complications after allogeneic stem cell transplantation are significantly associated with chronic graft-versus-host disease and with the graftversus-leukemia effect. Blood 2003; 102: 4236-4242.

21 Marras TK, Chan CK, Lipton JH, Messner HA, Szalai JP, Laupacis A. Long-term pulmonary function abnormalities and survival after allogeneic marrow transplantation. Bone Marrow Transplant 2004; 33: 509-517.
22 Chien JW, Martin PJ, Flowers ME, Nichols WG, Clark JG. Implications of early airflow decline after myeloablative allogeneic stem cell transplantation. Bone Marrow Transplant 2004; 33: 759-764.

23 Ratjen F, Rjabko O, Kremens B. High-dose corticosteroid therapy for bronchiolitis obliterans after bone marrow transplantation in children. Bone Marrow Transplant 2005; 36: 135-138

24 Khalid M, Al Saghir A, Saleemi S, et al. Azithromycin in bronchiolitis obliterans complicating bone marrow transplantation: a preliminary study. Eur Respir J 2005; 25: 490493.

25 Yoshihara S, Tateishi U, Ando T, et al. Lower incidence of bronchiolitis obliterans in allogeneic hematopoietic stem cell transplantation with reduced-intensity conditioning compared with myeloablative conditioning. Bone Marrow Transplant 2005; 35: 1195-1200.

26 Santo Tomas LH, Loberiza FR Jr, Klein JP, et al. Risk factors for bronchiolitis obliterans in allogeneic hematopoietic stem-cell transplantation for leukemia. Chest 2005; 128: 153-161.

27 Afessa B, Litzow MR, Tefferi A. Bronchiolitis obliterans and other late onset non-infectious pulmonary complications in hematopoietic stem cell transplantation. Bone Marrow Transplant 2001; 28: 425-434.

28 Paz HL, Crilley P, Patchefsky A, Schiffman RL, Brodsky I. Bronchiolitis obliterans after autologous bone marrow transplantation. Chest 1992; 101: 775-778.

29 Frankovich J, Donaldson SS, Lee Y, Wong RM, Amylon M, Verneris MR. High-dose therapy and autologous hematopoietic cell transplantation in children with primary refractory and relapsed Hodgkin's disease: atopy predicts idiopathic diffuse lung injury syndromes. Biol Blood Marrow Transplant 2001; 7: 49-57.

30 Ohnuma K, Toyoda Y, Ishida Y, et al. Fatal obstructive lung disease after haploidentical sibling cord blood transplantation. Bone Marrow Transplant 1998; 21: 939-941.

31 Endo M, Furukawa H, Aramaki T, et al. Unusual late pulmonary complication in a child after umbilical cord blood transplantation: high-resolution CT-pathologic correlation. J Thorac Imaging 2005; 20: 103-106.

32 Prince DS, Wingard JR, Saral R, Santos GW, Wise RA. Longitudinal changes in pulmonary function following bone marrow transplantation. Chest 1989; 96: 301-306.

33 Chien JW, Maris MB, Sandmaier BM, Maloney DG, Storb RF, Clark JG. Comparison of lung function after myeloablative and $2 \mathrm{~Gy}$ of total body irradiation-based regimens for hematopoietic stem cell transplantation. Biol Blood Marrow Transplant 2005; 11: 288-296.

34 Marras TK, Chan CK. Obliterative bronchiolitis complicating bone marrow transplantation. Semin Respir Crit Care Med 2003; 24: 531-542.

35 Ralph DD, Springmeyer SC, Sullivan KM, Hackman RC, Storb R, Thomas ED. Rapidly progressive air-flow obstruction in marrow transplant recipients. Possible association between obliterative bronchiolitis and chronic graft-versus-host disease. Am Rev Respir Dis 1984; 129: 641-644.

36 Epler GR. Bronchiolitis obliterans and airways obstruction associated with graft-versus-host disease. Clin Chest Med 1988; 9: 551-556. 
37 Galanis E, Litzow MR, Tefferi A, Scott JP. Spontaneous pneumomediastinum in a patient with bronchiolitis obliterans after bone marrow transplantation. Bone Marrow Transplant 1997; 20: 695-696.

38 Cazzadori A, Di Perri G, Bonora S, Lanzafame M, Allegranzi B, Concia E. Fatal pneumothorax complicating BAL in a bone marrow transplant recipient with bronchiolitis obliterans. Chest 1997; 111: 1468-469.

39 Kumar S, Tefferi A. Spontaneous pneumomediastinum and subcutaneous emphysema complicating bronchiolitis obliterans after allogeneic bone marrow transplantation case report and review of literature. Ann Hematol 2001; 80: 430-435.

40 Garg K, Lynch DA, Newell JD, King TE Jr. Proliferative and constrictive bronchiolitis: classification and radiologic features. Am J Roentgenol 1994; 162: 803-808.

41 Jung JI, Jung WS, Hahn ST, Min CK, Kim CC, Park SH. Bronchiolitis obliterans after allogenic bone marrow transplantation: HRCT findings. Korean J Radiol 2004; 5: 107-113.

42 Padley SP, Adler BD, Hansell DM, Muller NL. Bronchiolitis obliterans: high resolution CT findings and correlation with pulmonary function tests. Clin Radiol 1993; 47: 236-240.

43 Lee ES, Gotway MB, Reddy GP, Golden JA, Keith FM, Webb WR. Early bronchiolitis obliterans following lung transplantation: accuracy of expiratory thin-section CT for diagnosis. Radiology 2000; 216: 472-477.

44 Bankier AA, Van Muylem A, Knoop C, Estenne M, Gevenois PA. Bronchiolitis obliterans syndrome in heartlung transplant recipients: diagnosis with expiratory CT. Radiology 2001; 218: 533-539.

45 Boehler A, Estenne M. Post-transplant bronchiolitis obliterans. Eur Respir J 2003; 22: 1007-1018.

46 Soubani AO, Miller KB, Hassoun PM. Pulmonary complications of bone marrow transplantation. Chest 1996; 109: 1066-1077.

47 Trisolini R, Bandini G, Stanzani M, et al. Morphologic changes leading to bronchiolitis obliterans in a patient with delayed non-infectious lung disease after allogeneic bone marrow transplantation. Bone Marrow Transplant 2001; 28: 1167-1170.

48 St John RC, Gadek JE, Tutschka PJ, Kapoor N, Dorinsky PM. Analysis of airflow obstruction by bronchoalveolar lavage following bone marrow transplantation. Implications for pathogenesis and treatment. Chest 1990; 98: 600-607.

49 Hauber HP, Mikkila A, Erich JM, et al. TNF- $\alpha$, interleukin-10 and interleukin-18 expression in cells of the bronchoalveolar lavage in patients with pulmonary complications following bone marrow or peripheral stem cell transplantation: a preliminary study. Bone Marrow Transplant 2002; 30: 485-490.

50 Chan C, Spaner D, Hyland R. Bronchiolitis obliterans after bone marrow transplantation. Blood 1989; 73: 355-356.

51 Yousem SA. The histological spectrum of pulmonary graft-versus-host disease in bone marrow transplant recipients. Hum Pathol 1995; 26: 668-675.

52 Estenne M, Maurer JR, Boehler A, et al. Bronchiolitis obliterans syndrome 2001: an update of the diagnostic criteria. J Heart Lung Transplant 2002; 21: 297-310.
53 Patterson GM, Wilson S, Whang JL, et al. Physiologic definitions of obliterative bronchiolitis in heart-lung and double lung transplantation: a comparison of the forced expiratory flow between $25 \%$ and $75 \%$ of the forced vital capacity and forced expiratory volume in one second. $J$ Heart Lung Transplant 1996; 15: 175-181.

54 Reynaud-Gaubert M, Thomas P, Badier M, Cau P, Giudicelli R, Fuentes P. Early detection of airway involvement in obliterative bronchiolitis after lung transplantation. Functional and bronchoalveolar lavage cell findings. Am J Respir Crit Care Med 2000; 161: 19241929.

55 Estenne M, Van Muylem A, Knoop C, Antoine M. Detection of obliterative bronchiolitis after lung transplantation by indexes of ventilation distribution. Am J Respir Crit Care Med 2000; 162: 1047-1051.

56 Ouwens JP, van der Mark TW, Koeter GH, de Boer WJ, Grevink RG, van der Bij W. Bronchiolar airflow impairment after lung transplantation: an early and common manifestation. J Heart Lung Transplant 2002; 21: 10561061.

57 Fanfulla F, Locatelli F, Zoia MC, et al. Pulmonary complications and respiratory function changes after bone marrow transplantation in children. Eur Respir J 1997; 10: 2301-2306.

58 Filipovich AH, Weisdorf D, Pavletic S, et al. National Institutes of Health consensus development project on criteria for clinical trials in chronic graft-versus-host disease: I. Diagnosis and staging working group report. Biol Blood Marrow Transplant 2005; 11: 945-956.

59 Freudenberger TD, Madtes DK, Curtis JR, Cummings P, Storer BE, Hackman RC. Association between acute and chronic graft-versus-host disease and bronchiolitis obliterans organizing pneumonia in recipients of hematopoietic stem cell transplants. Blood 2003; 102: 3822-3828.

60 Au WY, Ho JC, Lie AK, et al. Respiratory ciliary function in bone marrow recipients. Bone Marrow Transplant 2001; 27: 1147-1151.

61 Vilchez RA, Dauber J, Kusne S. Infectious etiology of bronchiolitis obliterans: the respiratory viruses connection - myth or reality? Am J Transplant 2003; 3: 245-249.

62 Hall CB. Respiratory syncytial virus and parainfluenza virus. N Engl J Med 2001; 344: 1917-1928.

63 Hadjiliadis D, Duane Davis R, Steele MP, et al. Gastroesophageal reflux disease in lung transplant recipients. Clin Transplant 2003; 17: 363-368.

64 Davis RD Jr, Lau CL, Eubanks S, et al. Improved lung allograft function after fundoplication in patients with gastroesophageal reflux disease undergoing lung transplantation. J Thorac Cardiovasc Surg 2003; 125: 533-542.

65 Benden C, Aurora P, Curry J, Whitmore P, Priestley L, Elliott MJ. High prevalence of gastroesophageal reflux in children after lung transplantation. Pediatr Pulmonol 2005; 40: 68-71.

66 Ing AJ. Interstitial lung disease and gastroesophageal reflux. Am J Med 2001;111: Suppl. 8A, 41S-44S.

67 Cooke KR, Krenger W, Hill G, et al. Host reactive donor T cells are associated with lung injury after experimental allogeneic bone marrow transplantation. Blood 1998; 92: 2571-2580. 
68 Holler E, Kolb HJ, Moller A, et al. Increased serum levels of tumor necrosis factor $\alpha$ precede major complications of bone marrow transplantation. Blood 1990; 75: 1011-1016.

69 Rowbottom AW, Riches PG, Downie C, Hobbs JR. Monitoring cytokine production in peripheral blood during acute graft-versus-host disease following allogeneic bone marrow transplantation. Bone Marrow Transplant 1993; 12: 635-641.

70 Kallio EA, Koskinen PK, Aavik E, Vaali K, Lemstom KB. Role of nitric oxide in experimental obliterative bronchiolitis (chronic rejection) in the rat. J Clin Invest 1997; 100: 2984-2994.

71 Gabbay E, Walters EH, Orsida B, et al. Post-lung transplant bronchiolitis obliterans syndrome (BOS) is characterized by increased exhaled nitric oxide levels and epithelial inducible nitric oxide synthase. Am J Respir Crit Care Med 2000; 162: 2182-2187.

72 Kanamori H, Fujisawa S, Tsuburai T, et al. Increased exhaled nitric oxide in bronchiolitis obliterans organizing pneumonia after allogeneic bone marrow transplantation. Transplantation 2002; 74: 1356-1358.

73 Crawford SW, Clark JG. Bronchiolitis associated with bone marrow transplantation. Clin Chest Med 1993; 14: 741-749.

74 Crawford SW. Supportive care in bone marrow transplantation: pulmonary complications. Cancer Treat Res 1997; 77: 231-254.

75 Ratanatharathorn V, Ayash L, Lazarus HM, Fu J, Uberti JP. Chronic graft-versus-host disease: clinical manifestation and therapy. Bone Marrow Transplant 2001; 28: 121-129.

76 Patriarca F, Skert C, Sperotto A, et al. Incidence, outcome, and risk factors of late-onset noninfectious pulmonary complications after unrelated donor stem cell transplantation. Bone Marrow Transplant 2004; 33: 751-758.

77 Heaton DC. Failure of thalidomide to control bronchiolitis obliterans post bone marrow transplant. Bone Marrow Transplant 1989; 4: 598.

78 Parker PM, Chao N, Nademanee A, et al. Thalidomide as salvage therapy for chronic graft-versus-host disease. Blood 1995; 86: 3604-3609.

79 Forsyth CJ, Cremer PD, Torzillo P, Iland HJ, Young GA. Thalidomide responsive chronic pulmonary GVHD. Bone Marrow Transplant 1996; 17: 291-293.

80 Rovelli A, Arrigo C, Nesi F, et al. The role of thalidomide in the treatment of refractory chronic graft-versus-host disease following bone marrow transplantation in children. Bone Marrow Transplant 1998; 21: 577-581.

81 Browne PV, Weisdorf DJ, DeFor T, et al. Response to thalidomide therapy in refractory chronic graft-versushost disease. Bone Marrow Transplant 2000; 26: 865-869.

82 Sano H, Kikuta A, Ito M, Nemoto K, Hojo H, Ohto H. [Successful treatment with combined anti-thymocyte globulin and methylprednisolone for bronchiolitis obliterans after allogeneic bone marrow transplantation in a child with chronic myelogenous leukaemia.]. Rinsho Ketsueki 2002; 43: 23-28.

83 Sullivan KM, Storek J, Kopecky KJ, et al. A controlled trial of long-term administration of intravenous immunoglobulin to prevent late infection and chronic graft-vs.-host disease after marrow transplantation: clinical outcome and effect on subsequent immune recovery. Biol Blood Marrow Transplant 1996; 2: 44-53.

84 Couriel DR, Hicks K, Giralt S, Champlin RE. Role of tumor necrosis factor- $\alpha$ inhibition with inflixiMAB in cancer therapy and hematopoietic stem cell transplantation. Curr Opin Oncol 2000; 12: 582-587.

85 Ishii T, Manabe A, Ebihara Y, et al. Improvement in bronchiolitis obliterans organizing pneumonia in a child after allogeneic bone marrow transplantation by a combination of oral prednisolone and low dose erythromycin. Bone Marrow Transplant 2000; 26: 907-910.

86 Gerhardt SG, McDyer JF, Girgis RE, Conte JV, Yang SC, Orens JB. Maintenance azithromycin therapy for bronchiolitis obliterans syndrome: results of a pilot study. Am J Respir Crit Care Med 2003; 168: 121-125.

87 Siddiqui J. Immunomodulatory effects of macrolides: implications for practicing clinicians. Am J Med 2004;117: Suppl. 9A, 26S-29S.

88 Speich R, Boehler A, Russi EW, Weder W. A case report of a double-blind, randomized trial of inhaled steroids in a patient with lung transplant bronchiolitis obliterans. Respiration 1997; 64: 375-380.

89 Whitford H, Orsida B, Kotsimbos $\mathrm{T}$, et al. Bronchoalveolar lavage cellular profiles in lung transplantation: the effect of inhaled corticosteroids. Ann Transplant 2000; 5: 31-37.

90 De Soyza A, Fisher AJ, Small T, Corris PA. Inhaled corticosteroids and the treatment of lymphocytic bronchiolitis following lung transplantation. Am J Respir Crit Care Med 2001; 164: 1209-1212.

91 Whitford H, Walters EH, Levvey B, et al. Addition of inhaled corticosteroids to systemic immunosuppression after lung transplantation: a double-blind, placebo-controlled trial. Transplantation 2002; 73: 1793-1799.

92 Zheng L, Walters EH, Wang N, et al. Effect of inhaled fluticasone propionate on BAL TGF- $\beta_{1}$ and bFGF concentrations in clinically stable lung transplant recipients. J Heart Lung Transplant 2004; 23: 446-455.

93 Foss FM. Extracorporeal photopheresis in the treatment of graft-vs-host disease. J Cutan Med Surg 2003; 7: Suppl. 4, 13-17.

94 Rossetti F, Zulian F, Dall'Amico R, Messina C, Montini G, Zacchello F. Extracorporeal photochemotherapy as single therapy for extensive, cutaneous, chronic graft-versushost disease. Transplantation 1995; 59: 149-151.

95 Foss FM, DiVenuti GM, Chin K, et al. Prospective study of extracorporeal photopheresis in steroid-refractory or steroid-resistant extensive chronic graft-versus-host disease: analysis of response and survival incorporating prognostic factors. Bone Marrow Transplant 2005; 35: 1187-1193.

96 Rook AH, Freundlich B, Jegasothy BV, et al. Treatment of systemic sclerosis with extracorporeal photochemotherapy. Results of a multicenter trial. Arch Dermatol 1992; 128: 337-346.

97 Truitt RL, Johnson BD, Hanke C, Talib S, Hearst JE. Photochemical treatment with S-59 psoralen and ultraviolet A light to control the fate of naive or primed $\mathrm{T}$ lymphocytes in vivo after allogeneic bone marrow transplantation. J Immunol 1999; 163: 5145-5156. 
98 Dall'Amico R, Rossetti F, Zulian F, et al. Photopheresis in paediatric patients with drug-resistant chronic graftversus-host disease. Br J Haematol 1997; 97: 848-854.

99 Child FJ, Ratnavel R, Watkins P, et al. Extracorporeal photopheresis (ECP) in the treatment of chronic graftversus-host disease (GVHD). Bone Marrow Transplant 1999; 23: 881-887.

100 Greinix HT, Volc-Platzer B, Rabitsch W, et al. Successful use of extracorporeal photochemotherapy in the treatment of severe acute and chronic graft-versus-host disease. Blood 1998; 92: 3098-3104.

101 Alcindor T, Gorgun G, Miller KB, et al. Immunomodulatory effects of extracorporeal photochemotherapy in patients with extensive chronic graftversus-host disease. Blood 2001; 98: 1622-1625.

102 Oyan B, Koc Y, Emri S, Kansu E. Improvement of chronic pulmonary graft-vs-host disease manifesting as bronchiolitis obliterans organizing pneumonia following extracorporeal photopheresis. Med Oncol 2006; 23: 125-129.

103 Calhoon JH, Levine S, Anzueto A, Bryan CL, Trinkle JK. Lung transplantation in a patient with a prior bone marrow transplant. Chest 1992; 102: 948.

104 Gascoigne A, Corris P. Lung transplants in patients with prior bone marrow transplants. Chest 1994; 105: 327.

105 Svendsen UG, Aggestrup S, Heilmann C, et al. Transplantation of a lobe of lung from mother to child following previous transplantation with maternal bone marrow. Eur Respir J 1995; 8: 334-337.

106 Heath JA, Kurland G, Spray TL, et al. Lung transplantation after allogeneic marrow transplantation in pediatric patients: the Memorial Sloan-Kettering experience. Transplantation 2001; 72: 1986-1990.

107 Boas SR, Noyes BE, Kurland G, Armitage J, Orenstein D. Pediatric lung transplantation for graft-versus-host disease following bone marrow transplantation. Chest 1994; 105: 1584-1586.

108 Rabitsch W, Deviatko E, Keil F, et al. Successful lung transplantation for bronchiolitis obliterans after allogeneic marrow transplantation. Transplantation 2001; 71: 1341-1343.

109 Sano Y, Date H, Nagahiro I, Aoe M, Shimizu N. Livingdonor lobar lung transplantation for bronchiolitis obliterans after bone marrow transplantation. Ann Thorac Surg 2005; 79: 1051-1052.
110 Lund MB, Kongerud J, Brinch L, Evensen SA, Boe J. Decreased lung function in one year survivors of allogeneic bone marrow transplantation conditioned with high-dose busulphan and cyclophosphamide. Eur Respir J 1995; 8: 1269-1274.

111 Heng D, Sharples LD, McNeil K, Stewart S, Wreghitt T, Wallwork J. Bronchiolitis obliterans syndrome: incidence, natural history, prognosis, and risk factors. J Heart Lung Transplant 1998; 17: 1255-1263.

112 Sharples LD, McNeil K, Stewart S, Wallwork J. Risk factors for bronchiolitis obliterans: a systematic review of recent publications. J Heart Lung Transplant 2002; 21: 271-281.

113 Swanson SJ, Mentzer SJ, Reilly JJ, et al. Surveillance transbronchial lung biopsies: implication for survival after lung transplantation. J Thorac Cardiovasc Surg 2000; 119: 27-37.

114 Norgaard MA, Andersen CB, Pettersson G. Does bronchial artery revascularization influence results concerning bronchiolitis obliterans syndrome and/or obliterative bronchiolitis after lung transplantation? Eur J Cardiothorac Surg 1998; 14: 311-318.

115 Boehler A, Estenne M. Obliterative bronchiolitis after lung transplantation. Curr Opin Pulm Med 2000; 6: 133-139.

116 Boehler A, Chamberlain D, Kesten S, Slutsky AS, Liu M, Keshavjee S. Lymphocytic airway infiltration as a precursor to fibrous obliteration in a rat model of bronchiolitis obliterans. Transplantation 1997; 64: 311-317.

117 Hertz MI, Taylor DO, Trulock EP, et al. The registry of the international society for heart and lung transplantation: nineteenth official report-2002. J Heart Lung Transplant 2002; 21: 950-970.

118 Estenne M, Hertz MI. Bronchiolitis obliterans after human lung transplantation. Am J Respir Crit Care Med 2002; 166: 440-444.

119 Bando K, Paradis IL, Similo S, et al. Obliterative bronchiolitis after lung and heart-lung transplantation. An analysis of risk factors and management. J Thorac Cardiovasc Surg 1995; 110: 4-13.

120 Iacono AT, Johnson BA, Grgurich WF, et al. A randomized trial of inhaled cyclosporine in lung-transplant recipients. N Engl J Med 2006; 354: 141-150. 